This study, part of the College of Occupational Therapists' Mental Health Project, surveyed occupational therapy managers in mental health to gather data about them, the services they managed and their opinions on current and future issues of importance. A questionnaire was sent to the 184 managers who it was believed worked in mental health and it achieved a $65.2 \%$ response rate.

The majority of the 120 respondents were female, with Head II therapists between the ages of 31 and 40 forming the largest group. Two-thirds had additional qualifications and $71 \%$ had worked in mental health for more than 11 years. In addition to managing occupational therapy services, $86 \%$ carried a caseload or managed other services. Aspects of professional management were ranked highest in a list of tasks undertaken. Contradictions were noted in the managers' opinions on recruitment and retention of staff and the importance of staff supervision. The managers displayed commitment to the principles and philosophy of occupational therapy and a determination to demonstrate its effectiveness through research and evidence-based practice.

This study contributed to the position paper on the way ahead for occupational therapy in mental health (Craik et al 1998a) and provided information for occupational therapy managers to assist them to review their role.

\title{
A National Survey of Occupational Therapy Managers in Mental Health
}

\author{
Christine Craik, Chris Austin and Donna Schell
}

\section{Introduction}

The College of Occupational Therapists (COT) established a Mental Health Project Working Group to produce a position paper on the way ahead for research, education and practice in occupational therapy in mental health (Craik et al 1998a). The project began with a review of the literature on occupational therapy in mental health (Craik 1998) which served as a foundation both for this study and for other aspects of the project. It revealed a dearth of information published in the United Kingdom (UK) about the practice and management of occupational therapy services in mental health.

Some aspects of management have featured in the literature, although not always in relation to mental health. Problems with the recruitment and retention of occupational therapists have been well documented, with the Blom-Cooper (1989) report highlighting the highest vacancy rates in learning disability and mental health. Borikar and Goodban (1989), investigating recruitment problems in South-East England, although not specilically in mental health, found that the 121 occupational therapists they surveyed looked for multiprofessional teamwork, opportunities for further training and structured support and supervision in choosing a post. They would be deterred by a service with a poor reputation, rigid hours, a poorly organised informal visit and a perceived lack of support. A survey of 25 occupational therapists in Northern Ireland by Jenkins (1991) also found that multiprofessional teamwork and further training, along with adequate staffing and involvement in decision making, contributed to job satisfaction and hence retention. Deterrents to recruitment and retention were lack of resources, unrealistic workloads, personal reasons and lack of professional status. In a more recent study of 67 occupational therapists in a mental health trust, Richards (1998) found that the factors most influencing retention were working in mental health; good staff relations; geographical area; staff development opportunities; and opportunities for specialist practice. Staff also wanted a higher profile for the profession and more training and development.

Given the importance of recruitment and retention, the lack of research in this area is disappointing. Although an account has been developed of the factors that occupationil therapists consider important for their recruitment and retention, further research could verify this.

Studying the transition from student to therapist, 51 newly qualified staff in Parkers (1991) survey identified poor recognition by other professionals as the principal aspect that restricted job satisfaction and supervision as the most popular strategy to ease the transition. Rugg (1996, pl67), in her study of 177 occupational therapists, noted that 'getting adequate supervision' was one of the three principal factors where there was a statistically significant difference (at the $p<0.001$ level) between the situation respondents considered would be ideal prior to qualification and what they expected to happen after qualification.

In a survey of 310 occupational therapists, Sweency et al (1993a) revealed that stress in junior staff was often related to patient contact. Sweeney et al (1993b) later suggested 
supervision from a manager on a weekly basis as the first in a series of strategies to cope with stress. In Leonard and Corr's (1998) study of 62 recently qualified therapists, inclividual supervision and informal discussion with occupational therapists were the two most popular methods of coping with stress. They stated that 'many therapists have access to support and supervision and appear to be using them; however, the quality and extent of these is unknown' (Leonard and Corr 1998, p261). In a study of stress and supervision, Allan and Ledwith (1998) noted that around one-third of 210 occupational therapists recounted high or very high levels of stress. Only $25 \%$ were satisfied with their level of supervision and $40 \%$ wanted more supervision, especially those who experienced most stress and those who stated their intention to leave the profession.

Again, having documented the opinion of occupational therapists, further studies could establish if additional supervision would indeed reduce levels of stress and improve recruitment and retention.

In a qualitative study of 15 National Health Service (NHS) occupational therapy staff about their views on the impact of moving to trust status, Lloyd-Smith (1997, p310) observed that the need to justify and market the role of occupational therapy was a theme that was 'raised by all grades of staff and was a subject to which they returned during the interviews'. Strong professional leadership was valued as a means of combating fragmentation and loss of professional direction.

It can be seen that only certain aspects of management, principally personnel and marketing, have been reported in the literature.

\section{Aims of the research}

Having established the scarcity of information published in the UK about the practice and management of occupational therapy services in mental health, this aspect of the mental health project focused on occupational therapy managers and endeavoured to gather data about them. It aimed to:

1. Determine the profile of occupational therapy managers in mental health in the UK

2. Describe the occupational therapy services they managed and the management tasks they performed

3. Identify current and future issues of importance to occupational therapy managers in mental health.

\section{Method}

A survey methodology was adopted, using a questionnaire designed to complement the one used in the practitioners survey (Craik et al 1998b). Development of this questionnaire was influenced by the literature and by the responses to the practitioners survey. Some questions from the practitioners survey were repeated where comparison was considered to be advantageous and more multiplechoice questions were included to facilitate analysis.

\section{Sample}

To access the managers, the COT's mailing list was used. As few managers in social services work exclusively in mental health, they were excluded. Of the 950 managers in the NHS or private health sector, 50 were readily identified as managing a mental health service. The Health and Social Services Year Book 1997/98 (Institute of Health Service Management 1997) was used to identify further services that were principally, or included, mental health. This resulted in a total of 184 occupational therapy managers who it was believed worked in mental health. The questionnaire was posted to them, with a covering letter and a stamped addressed envelope. Confidentiality was assured, although respondents were invited to provide their name and address if they were willing to participate in further studies.

\section{Results}

Of the 184 questionnaires, 4 (2\%) were returned not answered because the recipient did not work in mental health and 120 were returned completed, representing a $65.2 \%$ response rate. The results were analysed using the Statistical Package for Social Sciences (SPSS) and by content analysis. Unless otherwise stated, the results are based on replies from all respondents.

\section{Profile of the occupational therapy managers}

\section{Gender}

Twelve (10\%) respondents were male and $108(90 \%)$ were female.

\section{Age-group and grade of post}

The largest number of respondents $(52,43 \%)$ were in the 31 40 age-group. Using the Whitley Council scale and some additional categories, all respondents stated the grade of their

Fig. 1. Age-group of 120 occupational therapy managers according to grade.

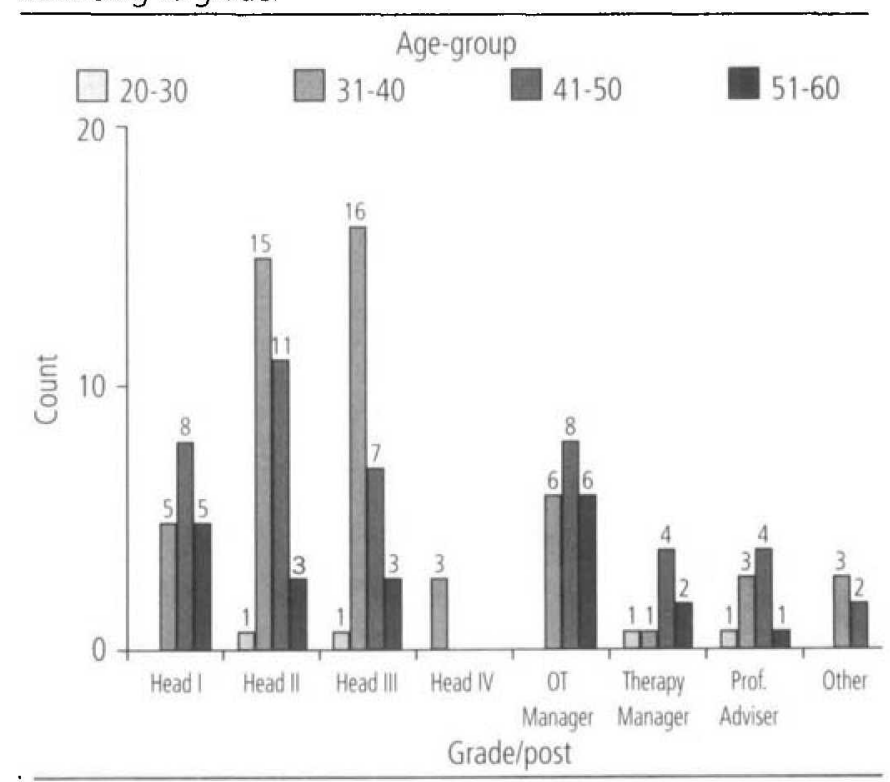


current post. The most frequent grade was Head II, with 30 (25\%) respondents. The results are displayed in Fig.l.

\section{Other grades and titles}

Five managers gave an alternative grade or title and a further $30(25 \%)$ managers had a second grade or title of whom four managers had a third title, creating a total of 39 titles. These were categorised, with Professional Adviser emerging as the most frequently used 'other' title, reported by 14 respondents. Therapy Manager or Coordinator was noted by eight respondents with Occupational Therapy Service Manager stated by five respondents. The remaining titles were too diverse to categorise.

\section{Occupational therapy qualification}

One hundred and seventeen (97.5\%) managers had a Diploma of the College of Occupational Therapists (DipCOT), two had a BSc Occupational Therapy and one had a Postgraduate Diploma in Occupational Therapy.

\section{Additional qualifications}

The managers indicated their additional qualifications with four managers not responding. Seventy-six (66\%) managers had an additional qualification: 12 had a Master's degree, 21 had a Bachelor's degree and 28 had a management qualification. The 15 respondents who chose the 'other' option and a further 18 respondents had additional qualifications, two of whom had two other qualifications, making 35 in total. Ten of these related to clinical issues and seven to counselling, seven were additional management qualifications, four were an additional Bachelor's degree, four related to teaching and three were miscellaneous.

\section{Time worked in mental health}

All respondents recorded how long they had worked in mental health and in their current post. Eighty-five (71\%) had worked in mental health for more than 11 years with 39

Fig.2. Time in years worked in mental health and in current post of 120 occupational therapy managers.

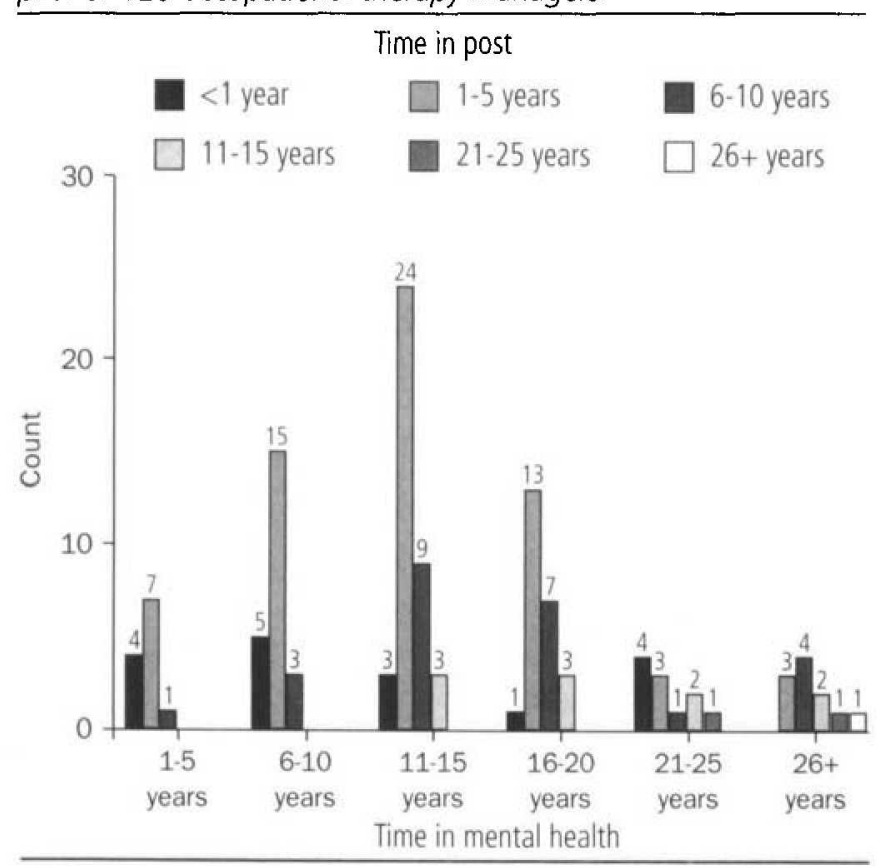

(32\%), forming the largest group, having worked in mental health for between 11 and 15 years. However, $82(68 \%)$ had been in their current post for less than 5 years. The results are shown in Fig. 2.

\section{Research}

Sixty-three (53\%) of the 118 managers who responded had personally carried out occupational therapy specific research, assisted someone else to do so or had done both. Within the group of 46 managers who had assisted someone else with research, 22 had done so by completing questionnaires and were disregarded, leaving 24 (20\%) of the 118 managers who had actually assisted with research. Nine of these managers had facilitated others, usually their staff, to carry out research.

Thirty-three (28\%) of the 118 managers had personally carried out research. One of these related to pre-registration education and was disregarded, leaving 32 (27\%) who had conducted research not connected to pre-registration education. Of those who gave examples which could be categorised, 15 related to management topics and 11 to clinical ones.

\section{Hours worked}

One hundred and six (88\%) managers worked full time and the remaining 14 worked part time. Those who worked part time were distributed throughout the grades of manager.

\section{Profession of line manager}

All 120 managers gave the title of their line manager and 88 (73\%) were able to use the categories provided, although 32 used the 'other' option. The results are displayed in Table 1.

The titles of the 32 'other' managers and those provided by nine managers with a second manager created 41 additional diverse titles. When grouped, 17 were categorised as Clinical Service Managers and Services Directors, six were Therapy Managers, four were Mental Health Managers, three were Nurse Managers and the remaining 11 respondents reported to managers with a variety of titles.

\section{Table 1. Profession of the line manager of the $\mathbf{1 2 0}$} occupational therapy managers

\begin{tabular}{|c|c|c|}
\hline Profession & Frequency & Percentag \\
\hline \multicolumn{3}{|c|}{ 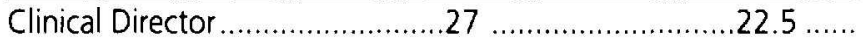 } \\
\hline \multicolumn{3}{|l|}{ General Manager } \\
\hline \multicolumn{3}{|c|}{ OT Manager .................................. } \\
\hline \multicolumn{3}{|c|}{ Therapy Services Manager ...........7 _......................... $5.8 \ldots$} \\
\hline \multicolumn{3}{|c|}{ 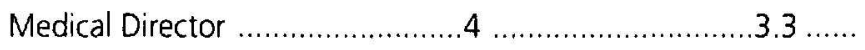 } \\
\hline \multicolumn{3}{|c|}{ 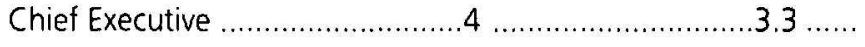 } \\
\hline \multicolumn{3}{|c|}{ 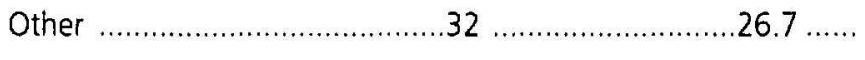 } \\
\hline \multicolumn{3}{|c|}{ 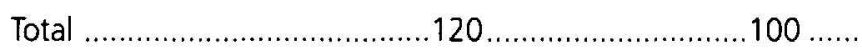 } \\
\hline
\end{tabular}

\section{Management of occupational therapy in mental health}

\section{Employer category}

All but four of the 120 managers were employed by an NHS trust. One had a post split between a trust and a local 
authority; two worked in a private charity; and one was in private practice. Sixty-three (54\%) managers worked in a mental health specialty and the remainder did not.

\section{Occupational therapy caseload}

Forty (33\%) managers did not have a clinical caseload and $80(67 \%)$ managers had a caseload. These 80 managers then estimated the percentage of their time spent in relation to their clinical duties. For 42 (52\%) of the 80 managers their cascload constituted less than a quarter of their working time, while for four therapists at Head III and Head IV grade it formed more than three-quarters of their time. The results according to the grade of the manager are displayed in Fig.3.

\section{Managing services other than occupational therapy}

Seventy (59\%) of 119 respondents managed only occupational therapy services while the remaining 49 (41\%) also managed other services. One respondent did not answer. These 49 respondents then estimated the percentage of their work that related to managing occupational therapy services, with $31(63 \%)$ of 49 managers spending more than half their time on the occupational therapy aspects of their role.

Of the 70 respondents who managed only occupational therapy services, $53(76 \%)$ had a caseload, leaving $17(14 \%)$ of the 119 managers who responded neither managing other services nor having a caseload.

\section{Management tasks}

In relation to managing occupational therapy staff, the respondents indicated their level of involvement in a variety of management tasks. The number of respondents answering each
Fig.3. Estimated percentage of time spent in relation to their clinical caseload of 80 occupational therapy managers according to grade.

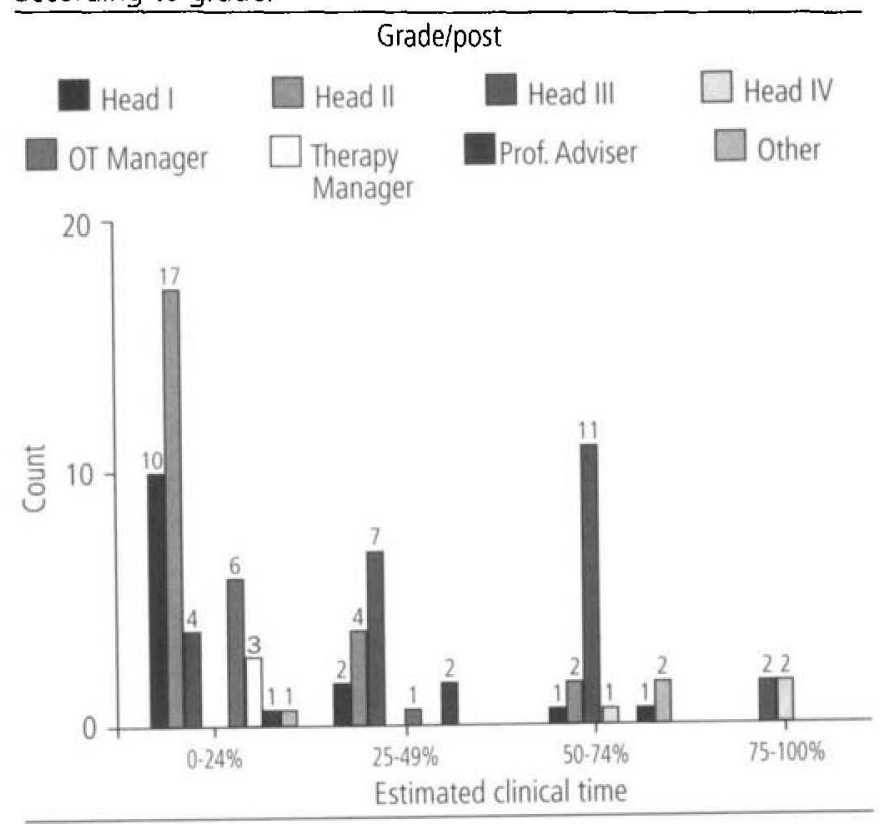

part of the question varied and the totals are shown in Table 2. The results are displayed in rank order of the percentage of managers who judged themselves 'responsible for' each task. To reduce the amount of data, only the percentages are shown.

The task with the highest score was professional supervision, where 112 (94.1\%) of 119 managers had responsibility. Next were a group of tasks where over $80 \%$ of those who responded considered that they had responsibility. These were representation of the occupational therapy service; individual performance review; recruitment of staff;

Table 2. Level of involvement in management tasks

\begin{tabular}{|c|c|c|c|c|c|}
\hline Task & $\begin{array}{l}\text { Responsible } \\
\text { for }(\%)\end{array}$ & $\begin{array}{l}\text { Involved } \\
\text { with (\%) }\end{array}$ & $\begin{array}{l}\text { Consulted } \\
\text { about (\%) }\end{array}$ & $\begin{array}{l}\text { N/A } \\
(\%)\end{array}$ & $\begin{array}{l}\text { Total } \\
\text { (No.) }\end{array}$ \\
\hline \multicolumn{6}{|l|}{ Professional supervision } \\
\hline \multicolumn{6}{|l|}{ Representation of OT .... } \\
\hline \multicolumn{6}{|l|}{ Individual performance review } \\
\hline \multicolumn{6}{|c|}{$\ldots . . .83 .2 \ldots \ldots \ldots \ldots \ldots . .14 .3 \ldots \ldots \ldots \ldots \ldots \ldots \ldots . . .2 .5 \ldots \ldots \ldots$} \\
\hline \multicolumn{6}{|c|}{ 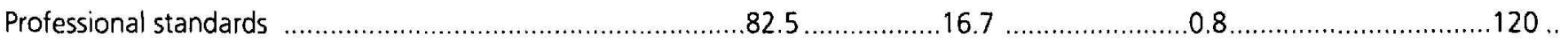 } \\
\hline \multicolumn{6}{|l|}{ Deployment of staff } \\
\hline \multicolumn{6}{|c|}{ 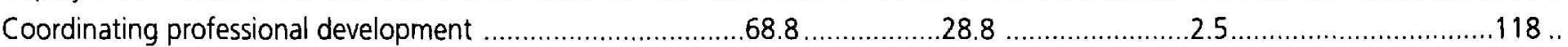 } \\
\hline \multicolumn{6}{|c|}{ 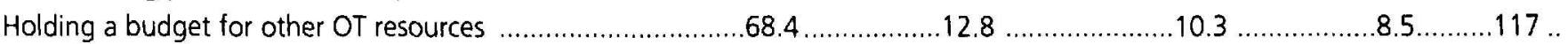 } \\
\hline \multicolumn{6}{|c|}{ 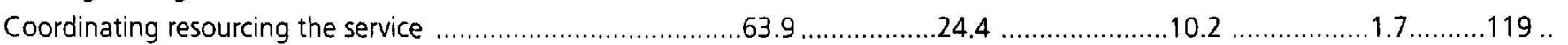 } \\
\hline \multicolumn{6}{|c|}{ 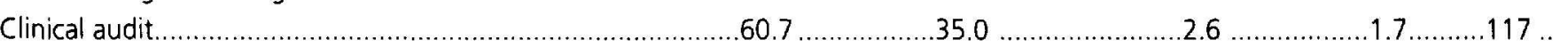 } \\
\hline \multicolumn{6}{|c|}{ 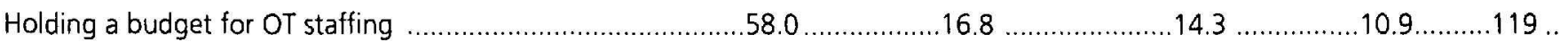 } \\
\hline \multicolumn{6}{|c|}{ 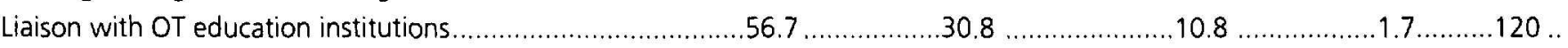 } \\
\hline \multicolumn{6}{|c|}{ 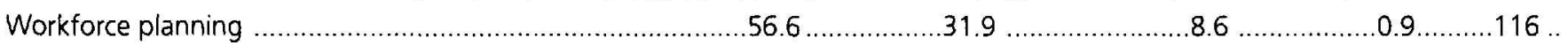 } \\
\hline \multicolumn{6}{|l|}{ Coordination OT students placements } \\
\hline \multicolumn{6}{|c|}{ 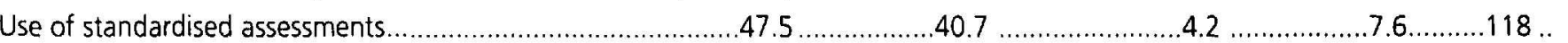 } \\
\hline \multicolumn{6}{|c|}{ 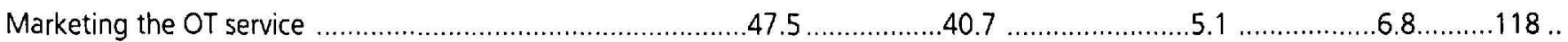 } \\
\hline \multicolumn{6}{|c|}{ 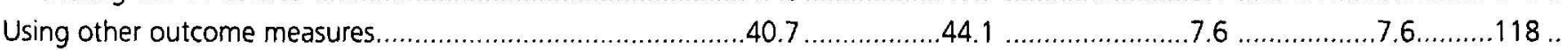 } \\
\hline \multicolumn{6}{|c|}{ 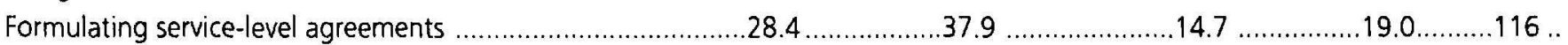 } \\
\hline \multicolumn{6}{|c|}{ 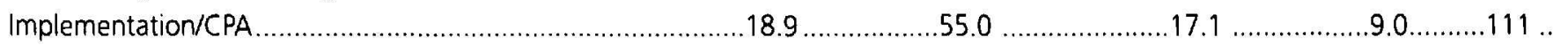 } \\
\hline \multicolumn{6}{|l|}{ Implementing HON outcome scales } \\
\hline \multicolumn{6}{|l|}{ Negotiating contracts with purchasers } \\
\hline
\end{tabular}


and professional standards. In contrast, the tasks for which the managers had least responsibility and which they indicated were not applicable were negotiating contracts with purchasers and implementing the Care Programme Approach (CPA) and the Health of the Nation (HON) outcome scales.

\section{Recruitment and retention of staff}

First, the managers assessed if the recruitment and retention of occupational therapy staff in their service had deteriorated, improved or remained the same over the past 3 years. The results of the 113 managers who responded to both parts of the question are shown in Fig.4. Those who considered that both recruitment and retention had improved formed the largest group at 37 (33\%) of 113 . Twenty-five (22\%) considered that although recruitment had improved, retention had remained the same. Twenty-eight (25\%) considered that both factors had remained the same, with five managers considering that both had deteriorated.

Next, managers ranked the importance of 10 factors in the recruitment and retention of occupational therapy staff and nominated other factors. Twenty-nine additional factors were offered, not all of which were ranked: 12 of these related to management structures, especially those that emphasised professional aspects; nine factors related to remuneration and promotion opportunities for staff; and the remainder were miscellaneous.

The managers considered a wide range of factors to be influential in the recruitment of staff, with staff supervision ranked highest by $24.3 \%$ of the 107 who responded to that part of the question. Training and development opportunities and clinical specialties were also considered important. There was closer agreement in the factors that influenced retention. Again, staff supervision was chosen as the most important by $29.5 \%$ and ranked second by $31.4 \%$ of the 105 managers who responded. Training and development opportunities were ranked first by $27.6 \%$ and second by $32.4 \%$ of these 105 managers.

To facilitate comparison, the rankings were then weighted. Those items ranked 1 were multiplied by a factor

Fig.4. Perception of 113 managers on the changes in the recruitment and retention of occupational therapy staff over the past 3 years.

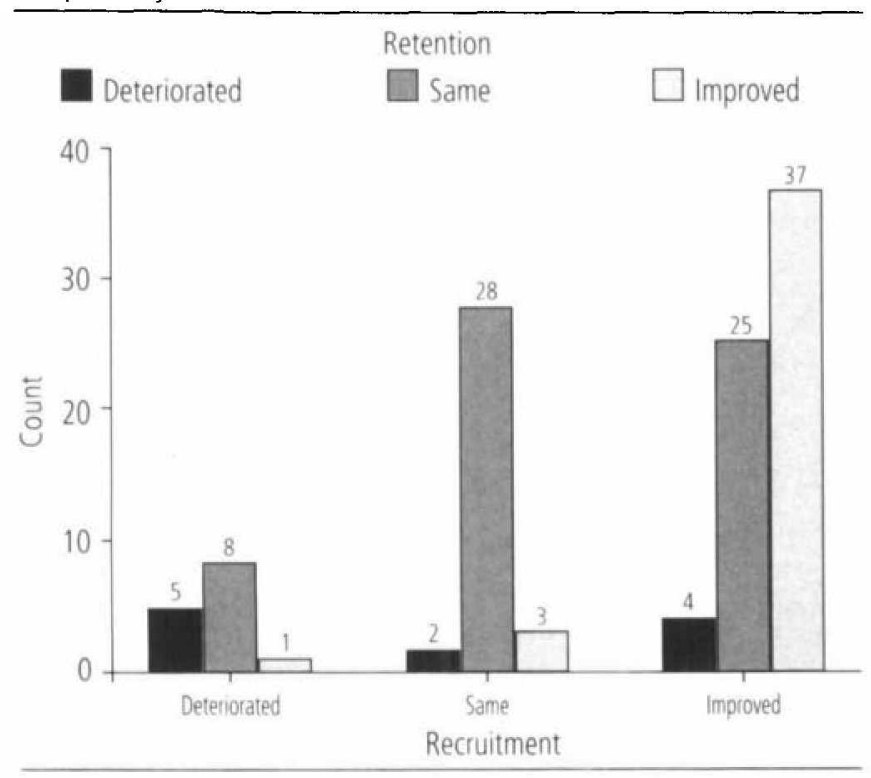

of 11 , those ranked 2 by a factor of 10 , those ranked 3 by 9 and so on. The results are shown in Table 3 in the weighted rank order of recruitment.

Again, supervision and training and development were clearly the most influential factors in both recruitment and retention, with staffing levels and skill mix and professional profile also influential to both but to a lesser extent. Clinical specialties and location scored more highly in recruitment and multidisciplinary team working in retention. Having a rotation scheme was not rated highly in recruitment or retention.

\section{Table 3. Weighted ranking of factors important in recruitment and retention of occupational therapy staff}

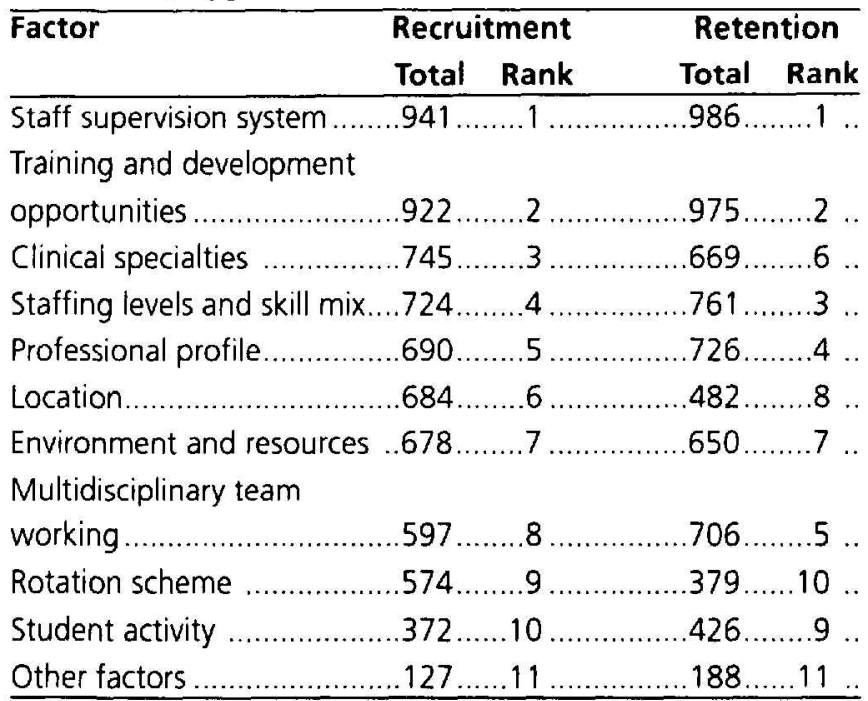

\section{Continuing professional development for occupational therapy staff}

Managers reported the number of days of continuing professional development (CPD) that their staff received each year. This question elicited the poorest response in the survey, with 15 (12.5\%) managers not responding to part of the question and some noting that they did not supervise that grade of staff. The total number responding to each part of the question is depicted in Table 4.

The responses show similarity in the number of days of CPD received by qualified staff; $78 \%-87 \%$ of staff had 5 days or more per year, with those at Senior grades having the most. In contrast, $55 \%$ of helper and technical instructor staff had 5 days or more per year, with 3 days being the most frequent number. Additional comments revealed further disparity: some respondents highlighted special packages for specific grades of staff while one manager recorded only one half-day CPD per year for Head and Senior occupational therapists.

Table 4. Report by managers of the number of days of CPD received each year by grade of staff

\begin{tabular}{|c|c|c|c|c|c|}
\hline \multirow[t]{2}{*}{ Grade } & \multirow{2}{*}{$\begin{array}{c}\text { None } \\
\text { No. }(\%)\end{array}$} & \multirow{2}{*}{$\begin{array}{r}3 \text { days } \\
\text { No. }(\%)\end{array}$} & \multirow{2}{*}{$\begin{array}{c}5 \text { days } \\
\text { No. }(\%)\end{array}$} & \multicolumn{2}{|c|}{ Over 5 days } \\
\hline & & & & No. $(\%)$ & Total \\
\hline & $2(1$ & 46( & 241 & & 106 \\
\hline 76 & $.1(0.9)$ & 16 & 31 & & 07 \\
\hline & 1001 & 121 & 301 & & 111 \\
\hline Eaus. & $2(1.9)$ & $.21(20.0)$ & $32(30.5)$ & $.50(47.6)$ &. .105 \\
\hline
\end{tabular}




\section{Frequency of supervision of occupational therapy staff}

The managers reported the frequency of supervision that their staff received and the different number responding to each part of the question is displayed in Table 5. Basic grade, helper and technical instructor slaff received the most supervision; more than half the basic grade staft and onethird of the support staff received supervision weekly.

Table 5. Report by managers of the frequency of supervision received by grade of staff

\begin{tabular}{|c|c|c|c|c|c|}
\hline \multirow[t]{2}{*}{ Grade } & \multirow{2}{*}{$\begin{array}{r}\text { Infrequent } \\
\text { No. (\%) }\end{array}$} & \multirow{2}{*}{$\begin{array}{l}\text { Monthly } \\
\text { No. (\%) }\end{array}$} & \multicolumn{2}{|c|}{ Fortnightly Weekly } & \multirow[b]{2}{*}{ Tota } \\
\hline & & & No. (\%) & No. $(\%)$ & \\
\hline & $.5 \quad 14$ & & & ) & \\
\hline & $1 \quad(0.9)$ & & & & \\
\hline & .3 & & & & \\
\hline leads & $.23(20.5)$ & $.60(53.6)$ &. $.23(20.5)$ & $6(5.4)$ &. .112 \\
\hline
\end{tabular}

\section{Future issues in mental health}

The respondents provided up to three responses in order of importance to the open question 'Thinking of the future, what do you think are the three most important issues facing occupational therapists working in mental health?' All respondents gave a first and second response and 117 gave a third response. Many of the responses included two or more issues which made classification complex. Similar responses were grouped logether and then further analysed and clustered. The final set of issues and clusters was then compared with the original responses. Those issues identified only once have been excluded.

The most frequent issue was to clarify the core skills, approaches and roles of occupational therapists in the different mental health specialties, particularly in the emerging areas of the community and primary care teams. For example, occupational therapists should 'focus on core skills, not just group activity and counselling, other professionals can be involved in the latter'.

The issues in the next four clusters occurred with a similar frequency. First, there was a need to develop 'a culture of evidence-based practice', with time and funds for occupational therapy specific research in mental health which is a difficult area to evaluatc. This would help develop a research base for clinical practice and enable evidencebased practice, including the use of standardised assessments and 'effective outcome measures for mental health which clearly pinpoint the contribution occupational therapists make to multidisciplinary team intervention'.

Secondly, there was a nced for better marketing and promotion of occupational therapy to educate and persuade others of the value and contribution of the profession. This should include talking to purchasers, trust managers, general practitioners, other team members and carers and more presenting at conferences and publishing in journals. There was a 'need for occupational therapists nationally to speak with onc voice about clinical priorities'.

Thirdly, staffing establishments should be increased to reflect the increased workloads. Salaries and career structures should be reviewed to improve recruitment and retention, particularly as there was a 'lack of clinical specialist posts to assist career progression of clinicians and aid retention' and diminishing opportunities for occupational therapists to obtain professional management posts.

Fourthly, there was concern about intense pressures to become increasingly generic and less specialised, with a consequent loss of effectiveness and lower standards: 'to work as part of a real multidisciplinary team without becoming isolated or losing the true value of occupational therapy skills in a bid to fit in'. The skill mix debate was seen as suggesting the need for more generic workers and more, non-professionally qualified, support workers, which would further erode skills and effectiveness.

The remaining clusters accounted for about a quarter of the responses. These included 'responding to changes in mental health strategy and policy while retaining professional identity and core skills', for example care management, key working, and the shift towards a primary care focus. There was a clearly perceived need for occupational therapy specific and relevant CPD, particularly for working in the community. There was a need for management, supervision and support by occupational therapists, and opportunities for peer support, professional socialisation and networking amongst occupational therapists. The summary of the main clusters is shown in Table 6.

Table 6. Summary of the three most important issues facing occupational therapists working in mental health provided by managers

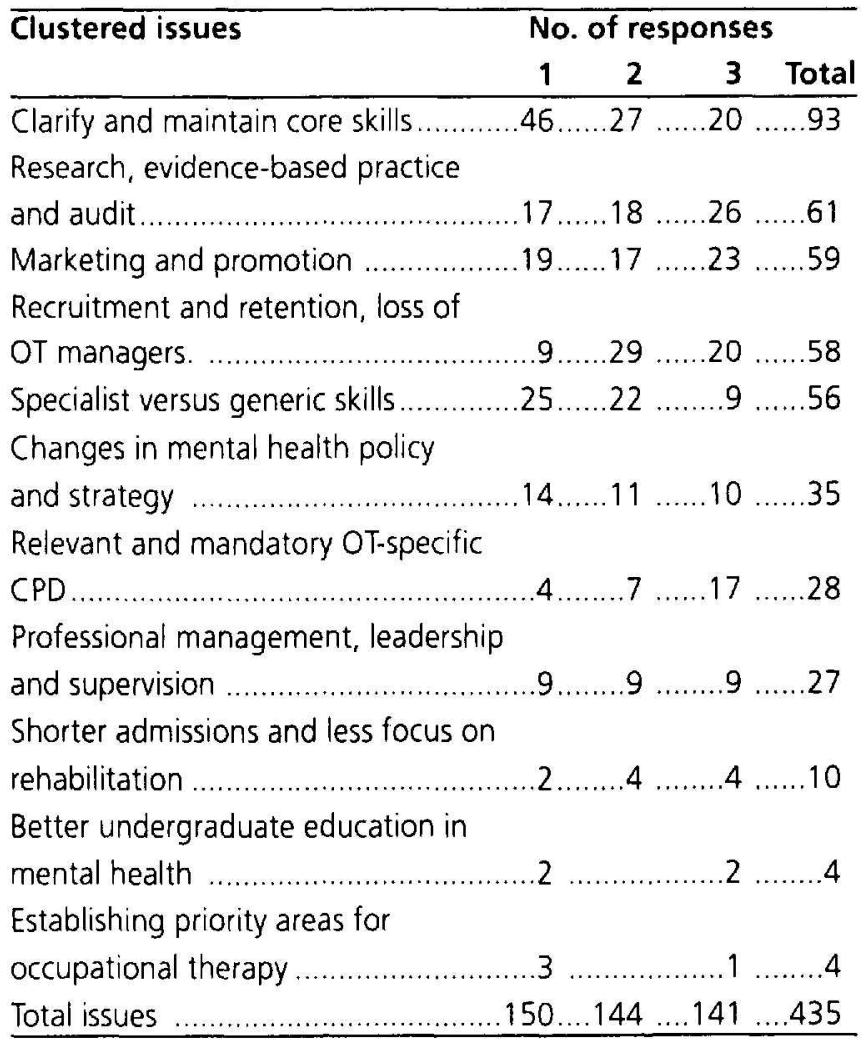

\section{Additional comments}

Thirty-one (26\%) of the 120 respondents provided additional comments. Their diversity mirrored the breadth of the issues previously identified. In particular, there was 
concern about role blurring and generic working and disillusionment about community-based work. Some respondents wanted feedback on the results of the survey or opportunities for networking

\section{Discussion}

The response rate at $65.2 \%$ was good, although slightly less than that for the practitioners survey at $68.5 \%$ (Craik et al 1998b). The sampling attempted to include all occupational therapy managers of mental health services in the UK, although it was not possible to judge if this was achieved. Three-quarters of the managers responded to the invitation to provide their name to participate in follow-up studies and these responses suggested that the managers represented all areas of the UK.

\section{Age-group and grade of post}

Comparing the age-group and grade of post with those in the practitioners survey (Craik et al 1998b) indicated that $43 \%$ of the managers were in the 31-40 age-group, a decade older that the largest group of practitioners. The most frequently noted management grade was Head II with 25\% of the respondents compared with $43 \%$ of the practitioners at Senior I (Craik et al 1998b).

\section{Title and management of other services}

Although the managers had a variety of titles, $82 \%$ either used Whitley Council scales or had occupational therapy in their title. Twenty-five per cent of the managers also had a second title and $41 \%$ also managed other services. One of the concerns that prompted the mental health project was the loss of professional management. These results, taken with the data from the practitioners survey (Craik et al 1998b) which demonstrated that $62 \%$ of the 137 practitioners were managed by an occupational therapist, seem to refute this to some extent. However, only 17 of these managers had a post which just involved managing an occupational therapy service. So for the remainder it would appear that maintaining management of their occupational therapy service was at the expense of undertaking the additional responsibilities of managing other services or holding a clinical caseload. However, this study only included occupational therapy managers so areas without such management might show a different pattern.

\section{Additional training and experience}

As might be expected of the group of this age and seniority, the majority had a DipCOT. Nevertheless, two-thirds had additional qualifications and their commitment to personal development may have influenced their responses on related topics. The managers were experienced: $71 \%$ had worked in mental health for more than 11 years and only $10 \%$ for 5 years or less. However, two-thirds had been in their current post for less than 5 years, probably reflecting the changes in the NHS over recent years.

\section{Research}

Only $27 \%$ of the managers had conducted research not connected with their pre-registration education but more had assisted others, especially their staff. However, they recognised the need for evidence-based practice, outcome measures and research as the sccond most important issue facing the profession in mental health. Initially this may appear disappointing but, as few of these managers would have experienced any research component in their preregistration education and probably learned about research methodology during further training, this result is encouraging.

\section{Management tasks}

It is reassuring that the tasks where the occupational therapy managers had the highest level of responsibility were those related to professional activities. However, the managers had less responsibility for some professional aspects, such as the use of standardised assessments and outcomes measures. This may be related to the low use of these recorded by practitioners (Craik et al 1998b). Professional supervision achieved the highest ranking, with 112 (94.1\%) managers being responsible for this, confirming the results of the practitioners survey (Craik et al 1998b) where $85 \%$ of the 137 respondents received supervision from another occupational therapist.

\section{Supervision}

Studying the detail of the supervision received by the staff of these managers revealed some disquieting findings. The COT's (1997) Statement on Supervision suggests monthly supervision for established professionals and $97.5 \%$ of senior occupational therapists received supervision monthly or more frequently. In contrast, the managers reported that only $53 \%$ of their basic grade staff received weekly supervision, which is the level recommended by the COT for new practitioners. This reinforces the results of the practitioners survey (Craik et al 1998b), where senior occupational therapists were also more likely than basic grade staff to receive the frequency of supervision recommended by the COT. Taken together, these results provide a partial response to Leonard and Corr's (1998) statement about the extent of supervision received by occupational therapists, although there was no attempt to assess its quality or effectiveness.

These findings endorse the opinion of two recent studies. First, the reality of recent graduates receiving adequate supervision post-qualification was significantly less than their ideal situation prior to qualification (Rugg 1996) and, secondly, only a quarter of 210 therapists were satisfied with their level of supervision (Allan and Ledwith 1998).

Given the opinions of the managers and the importance of supervision in easing the transition from student to practitioner (Parker 1991), in combating stress (Sweeney ct al 1993b, Leonard and Corr 1998) and in recruitment and retention (Borikar and Goodban 1989), the results are unexpected and merit further study. 


\section{Recruitment and retention}

While the intention of establishing the total number and location of occupational therapy staff was beyond the scope of this study, two questions attempted to estimate the number of staff in post and of vacancies. Due to the complexity of the questions and the number of incomplete answers, it was not possible to analyse the data.

Nevertheless, the respondents commented on the changes to recruitment and retention over the previous 3 years. This produced one of the most optimistic responses of the study.

One-third of managers considered that both recruitment and retention had improved over the 3 years and only five thought the reverse. However, when identifying the issues important for the future of the prolession, recruitment and retention were included in one of the clusters that achieved the second highest rating. These findings may not be contradictory. It may be that although recruitment and retention have improved over the past 3 years, the spectre of past difficulties remains to haunt the present.

A further contradiction emerged in relation to recruitment and retention. The managers ranked supervision as the most important factor in recruitment and retention and also reported a high degree of responsibility for supervision. However, they reported that only $53 \%$ of their basic grade therapists received the level of supervision advised by the COT. Increasing supervision for basic grade staff to the COT recommendation would be obvious advice. More fundamental is the need to explore the inconsistency in altitudes to supervision in relation to recruitment and retention.

The managers considered training and development opportunities as the second most important factor in both recruitment and retention, agrceing with the findings of Borikar and Goodban (1989), Jenkins (1991) and Richards (1998). In comparison to Richards (1998), clinical specialties were also judged influential in recruitment and retention but location was not. In contrast to the literaturc (Borikar and (joodban 1989, Jenkins 1991), multidisciplinary team working did not rate highly in recruitment and retention, supporting the findings of the practitioners survey where it did not feature among the reasons therapists gave for working in mental health (Craik et al 1998b).

\section{Continuing professional development}

Confirming their support for training and development and their management responsibility for coordinating professional development, the managers reported that about $80 \%$ of the occupational therapists they managed engaged in 5 days or more CPD each year. The managers also highlighted the need for occupational therapy specific CPD, recognising it as an important issue for the future. This is relevant not only for recruitment and retention but also in relation to the revision of the Professions Supplementary to Medicine Act (1960), which is likely to make CPD mandatory (Craik 1997). Whether these 5 days were focused directly on competence to practise and whether that frequency would be considered sufficient were not established. Although support staff will not be included in the proposed Act, it is disappointing to note the lower levels of CPD afforded to these staff. Taken with the managers' concern about pressure towards generic working, especially for support staff, this is surprising and creates an opportunity for improvement.

\section{Future issues}

The need for improved marketing and promotion of occupational therapy was recognised as an issue for the future, although less than half of the managers had responsibility for this, with $40 \%$ stating that they were involved with it. This may be an opportunity for action, given the findings of Parker (1991) who identified that poor recognition restricted job satisfaction; Jenkins (1991) who noted lack of professional status as a deterrent to recruitment and retention; Lloyd-Smith (1997) who observed the need to justify and market the profession; and Richards (1998) who found that staff wanted a higher professional profile.

The most critical issue for the future was the need to focus on core skills, approaches and roles and contrasted with the concern about the pressures to move to generic working. This echoed similar views from the practitioners survey (Craik et al 1998b). This theme was frequently repeated with some powerful and poignant descriptions: 'Not getting subsumed into an amorphous mass called the multidisciplinary team but maintaining our professional core skills and expertise' and 'Maintaining specialist role under onslaught to become a more generic worker in mental health teams'.

However, the managers did not advocate an end to multidisciplinary team working; rather, they wanted to 'persuade managers of the value and skills of occupational therapy - especially when occupational therapists are "hidden" in teams'. They further acknowledged the ability of occupational therapists to be 'good multidisciplinary team members, able to contribute equally to the team's effectiveness' and to 'add to the functioning of the team whilst remaining clear that we are in the team as an occupational therapist not a generic therapist'.

\section{Conclusion}

The results of this study displayed great similarities to those of the practitioners survey (Craik et al 1998b). There was commitment to the value of occupational therapy in mental health, identification of similar issues facing the profession in the future and a recognition of the action to be taken in relation to evidence-based practice and research. There was willingness to collaborate with others in the multidisciplinary team but desire for recognition of the unique contribution of occupational therapy.

There is dissonance between the stated importance of supervision in relation to recruitment and retention and the level reported to be received by basic grade staff; this topic warrants further investigation. Recruitment and retention was still considered an important issue despite the recorded improvement in both, although the need to increase staffing 
levels was also recognised reinforcing the pivotal place of recruitment and retention in the management of occupational therapy services.

This study produced data which contributed to the development and recommendations of the College of Occupational Therapists' Position Paper on the Way Ahead for Research, Education and Practice in Mental Health (Craik et al 1998a). It also provided material that managers can use to evaluate their own service. Together, these activities can contribute to the future effectiveness of occupational therapists and their ability to respond to the needs of clients with mental health problems.

\section{Acknowledgements}

The authors would like to thank the managers who contributed to the study: the College of Occupational Therapists for establishing the project; John Chacksfield and Gabrielle Richards of the Project Working Group; Dominique Le Marchand and colleagues at the College; and Mary Flight, formerly of Brunel University.

\section{References}

Allan F, Ledwith F (1998) Levels of stress and perceived need for supervision in senior occupational therapy staff. British Journal of Occupational Therapy, 61(8), 346-50.

Blom-Cooper L (1989) Occupational therapy: an emerging profession in health care. Report of a commission of inquiry. London: Duckworth.

Borikar A, Goodban A (1989) Recruitment: an investigation into recruitment problems on occupational therapy. British Journal of Occupational Therapy, 52(10), 392-94.

College of Occupational Therapists (1997) Supervision in occupational therapy. Standards, Policies and Procedures, SPP 150 (A). London: COT.

Craik C (1997) Review of the Professions Supplementary to Medicine Act 1960: implications for occupational therapists. British Journal of Occupational Therapy, 60(7), 305-308.

Craik C (1998) Occupational therapy in mental health: a review of the literature. British Journal of Occupational Therapy, 61(5), 186-92.

Craik C, Austin C, Chacksfield JD, Richards G, Schell D (1998a) College of Occupational Therapists: Position Paper on the Way Ahead for
Research, Education and Practice in Mental Health. British Journal of Occupational Therapy, 61(9), 390-92.

Craik C, Chacksfield JD, Richards G (1998b) A survey of occupational therapy practitioners in mental health. British Journal of Occupational Therapy, 61(5), 227-34.

Institute of Health Service Management (1997) Health and social services year book 1997/98. London: FT Healthcare.

Jenkins M (1991) The problems of recruitment: a local study. British Journal of Occupational Therapy, 54(12), 449-52.

Leonard C, Corr 5 (1998) Sources of stress and coping strategies in basic grade occupational therapists. British Journal of Occupational Therapy, 61(6), 257-62.

Lloyd-Smith W (1997) Moving to trust status: the experience of staff of occupational therapy departments. British Journal of Occupational Therapy, 60(7), 309-14.

Parker CE (1991) The needs of newly qualified occupational therapists. British Journal of Occupational Therapy, 54(5), 164-68.

Richards G (1998) Working knowledge. Health Service Journal, 9 April, 30-31.

Rugg S (1996) The transition of junior occupational therapists to clinical practice: report of a preliminary study. British Journal of Occupational Therapy, 59(4), 165-68.

Sweeney GM, Nichols KA, Kline P (1993a) Job stress in occupational therapy: an examination of causative factors. British Journal of Occupational Therapy, 56(3), 89-93.

Sweeney GM, Nichols KA, Kline P (1993b) Job stress in occupational therapy: coping strategies, stress management and recommendations for change. British Journal of Occupational Therapy, 56(4), 140-45.

\section{Authors}

Christine Craik, MPhil, DMS, DipCOT, MIMgt, SROT, Director of Undergraduate Occupational Therapy Studies, Department of Health Studies, Brunel University, Osterley Campus, Borough Road, Isleworth, Middlesex TW7 5DU, and Chairman of the Mental Health Project Working Group of the College of Occupational Therapists.

Chris Austin, DipCOT, BA, SROT, Senior Occupational Therapist, Exeter and District Community Health NHS Trust.

Donna Schell, DipCOT, SROT, Head of Occupational Therapy, St Andrew's Hospital, Northampton. 